\title{
Prior Radiation Therapy of Affected Breast
}

National Cancer Institute

\section{Source}

National Cancer Institute. Prior Radiation Therapy of Affected Breast. NCI Thesaurus.

Code C156795.

An indication that an individual has previously received radiation treatment of their currently affected breast. 